\title{
The Relationship Between Pulmonary Function and Physical Function and Mobility in Community- Dwelling Elderly Women Aged 75 Years or Older
}

\author{
Tsutomu Abe, RPt, MS ${ }^{1-3)}$, TAKao SuZuki, MD, PhD ${ }^{4)}$, Hideyo Yoshida, MD, PhD ${ }^{5}$, \\ HiroyUKi SHIMADA, RPT, $\mathrm{PhD}^{4}$, NOBUO INOUE, $\mathrm{PhD}^{1)}$ \\ 1) Department of Frontier Health Sciences, Tokyo Metropolitan University \\ ${ }^{2)}$ Department of Health Science, Uekusagakuen University \\ 3) Itabashi Rehabilitation Home-visiting Nursing Station: 2-11 Hikawa-cho, Itabashi-ku, Tokyo, 173-0013 \\ Japan.TEL:+81 3-5943-3151,FAX:+81 3-5943-3152,E-mail: iamatomu@yahoo.co.jp \\ 4) National Center for Geriatrics and Gerontology \\ ${ }^{5)}$ Tokyo Metropolitan Institute of Gerontology
}

\begin{abstract}
Purpose] The purpose of the present study was to evaluate the relationship between pulmonary function and the physical function and mobility of community-dwelling elderly women aged $\geq 75$ years. [Methods] The subjects were 1,022 women aged $\geq 75$ years who were living in an urban environment. We measured their vital capacity (VC) and forced expiratory volume in $1 \mathrm{~s}$ (FEV1.0) by spirometry, and assessed their physical function and mobility. [Results] Older women exhibited inferior pulmonary function as well as reduced physical function and mobility. These findings highlight the impact of diminished pulmonary function on physical function in old age. [Conclusions] Women of advanced age have diminished pulmonary function, physical function, and mobility, and diminished pulmonary function is associated with declining physical function. When an examination is required, spirometry should be included as an examination modality for its diagnostic value.

Key words: Pulmonary function, Physical function and mobility, Elderly women
\end{abstract}

(This article was submitted Nov. 15, 2010, and was accepted Dec. 16, 2010)

\section{INTRODUCTION}

An investigation that estimated the characteristics of population dynamics in Japan over the next 50 years reported that only the proportion of elderly individuals aged $\geq 75$ years is expected to increase in the near future ${ }^{1)}$. We have never experienced so great an aging of the population in our society which is facing a future of relatively fewer children as well as a decline in the population. Among the elderly population aged $\geq 75$ years, declines in psychosomatic and vital functions frequently appear with aging. In particular, because women have a longer average life span, they will require healthcare for longer and the major reason for this is that the age-related changes in the muscular and skeletal systems are more remarkable in women than in $\mathrm{men}^{2)}$.

Older individuals are severely affected with regard to the performance of activities of daily living (ADL) due to a decline in physical function ${ }^{3-5)}$.

Many physiological functions deteriorate with increasing age, and pulmonary function is no exception. It is very important that we understand the physiological changes seen in the lungs with aging ${ }^{10,11)}$ as pulmonary function deteriorates linearly with age ${ }^{12}$. Respiratory effort increases with age due to costochondral calcification. In addition, elastic tissues in the lungs, such as in the alveoli, are degraded and the lungs expand ${ }^{13-15}$. Therefore, although the total lung capacity remains unchanged, the residual volume increases with age ${ }^{16-18)}$. Furthermore, the maximum expiratory and inspiratory muscular strengths deteriorate with increasing age ${ }^{19-21)}$. In addition spirometric measurements have shown that both vital capacity (VC) and forced expiratory volume in $1 \mathrm{~s}$ (FEV1.0) decline with age $^{22-24)}$.

Functional disorders negatively affect physical function and mobility, and it is generally acknowledged that diminishing physical function and mobility influence the quality of life ${ }^{25}$. Studies of physical function of the elderly are becoming more important ${ }^{6-9}$ ). Regarding the evaluation of the physical function of the elderly, diminished capabilities are commonly encountered in hand-grip strength, gait velocity, timed up-and-go (TUG) at a comfortable speed, and one leg standing time with eyes open. However, the contribution of pulmonary function to the decline in physical function has not been evaluated in any detail. As a result, the relationship between 
diminishing pulmonary function and physical function and mobility among the elderly population remains unclear.

The purpose of the present study was to evaluate the relationships between pulmonary function and physical function and mobility of community-dwelling elderly women aged $\geq 75$ years

\section{SUBJECTS AND METHODS}

\section{Subjects}

We performed systematic comprehensive mass health examinations for elderly women living in the community in order to devise new strategies to increase physical fitness and to prevent the need for long-term care ${ }^{2)}$. The participants in the examinations conducted in November 2008 were women aged $\geq 75$ years who were living in Itabashi-ku, Tokyo at that time. From among 1,289 women who provided consent, we included 1,022 women in the present study for whom complete data were available. For the examination, we invited each participant to a meeting and conducted a medical examination and verbal interview. After receiving an explanation of the nature of the study and evaluation methods, all subjects provided their informed consent to voluntarily participate. This study was approved by the Ethical Review Board of Tokyo Metropolitan Institute of Gerontology.

\section{Methods}

We measured VC and FEV1.0 by spirometry, and assessed physical function and mobility. We divided the participants by age into two groups (75-79 years and 80-84 years) and compared each measurement result between these groups to examine the influence of age. We also classified pulmonary functional disorders roughly into four categories based on ventilatory characteristics: 1) Normal; 2) Narrowing of the bronchi, and obstructive ventilatory impairment with inadequate expiration; 3) Restrictive ventilatory impairment with inadequate air intake due to insufficient thoracic movement; and 4) A mixed type of the disorders described in 2) and 3). We used these categories to compare each measurement result and examined the influence of these pulmonary functional disorders on the results.

The technical characteristics of the instruments used in addition to the training of technicians are important for obtaining reliable results and for quality control of spirometry. Staff members were specifically trained and received lectures aimed at teaching and reviewing the rationale and practice of spirometric procedures. All pulmonary function tests used in the present study were performed in accordance with the prescribed guidelines ${ }^{26)}$. Spirometry was performed using a Chest MI Spirometer (HI-801; Chest, Tokyo, Japan). Each study participant was informed about the methods used for measurements and was given an explanation of the procedures of the examination along with appropriate practice. Spirometric maneuvers were performed with the participants seated in a comfortable position, wearing a nose clip, and the participants expired air was fed to the spirometer via a mouthpiece. All technicians were instructed to perform a minimum of two maneuvers to ensure that the participants produced the highest possible peak flow rates. Participant's VC and FEV1.0 were measured after a rest period of several minutes between maneuvers. Satisfactory exhalation was considered to have been achieved if 1) there was no change in the exhaled volume (plateau on the volume-time curve) for $1 \mathrm{~s}$ after an exhalation time of at least $6 \mathrm{~s}, 2$ ) there was a reasonable duration or plateau in the volumetime curve, or 3) the participant was unable to continue to exhale. The spirometer automatically made the following calculations. Predicted VC $=[0.032 \times$ height $(\mathrm{cm})-0.018$ $\times$ age -1.178$]$. From the result obtained, $\% \mathrm{VC}=[\mathrm{VC}$ (measured) $/ \mathrm{VC}$ (predicted) $] \times 100$ and $\% \mathrm{FEV} 1.0=(\mathrm{FEV} 1.0$ $/ \mathrm{FVC}) \times 100$, where FVC indicates forced VC. We used $\% \mathrm{VC}$ and $\% \mathrm{FEV} 1.0$ for analysis.

The participants also underwent tests for hand-grip strength, knee joint extension strength, comfortable and maximal gait velocities, TUG at comfortable and maximal speeds, and one-leg standing time with eyes open. We evaluated hand-grip strength of the dominant hand with a hand-held dynamometer (TKK5401, Hata Company) and isometric contraction of knee joint extension on the dominant side with a mechanical dynamometer (F1, Anima Company). To test knee joint extension strength, we asked the participants to extend the knee joint through 90 degrees to the best of their ability. To test walking velocity, we asked the participants to walk on a straight and flat walkway, $11 \mathrm{~m}$ in length, once at their usual speed and once again at their maximum speed. Walking velocity was measured over a $5 \mathrm{~m}$ distance between marks at $3 \mathrm{~m}$ and 8 $\mathrm{m}$ marked from the end of the walkway. To test $\mathrm{TUG}^{27)}$, we asked participants to stand up from a chair, walk $3 \mathrm{~m}$, turnaround and walk another $3 \mathrm{~m}$, and then sit down on the chair. This task was performed once at the participants' usual speed and then again at their maximum speed. The TUG test was measured as a series of movements using a stopwatch. For the one leg standing time with eyes open, we asked participants to look straight ahead at a spot $1 \mathrm{~m}$ in front of them. We then asked them to stand on their preferred leg with their eyes open and hands dangling freely alongside their body. The time until balance was lost, up to a maximum of $60 \mathrm{~s}$, was recorded. We used the better of two trials for analysis.

We used the Life-Space Assessment (LSA) as an index of mobility ${ }^{28)}$. LSA is used to assess mobility associated with physical function, health condition, and instrumental ADL (IADL), which are necessary for evaluating the mobility of older individuals ${ }^{29}$ ). LSA is used to identify the distance over which a person reports moving during the 4 weeks prior to the assessment. The LS zones range from a person's bedroom to beyond their home town. Specific questions are: 1) "During the past 4 weeks, have you been to other rooms of your home besides the room where you sleep?" (level 1) 2) "During the past 4 weeks, have you been to an area immediately outside your home, such as your porch, deck, or patio, to the hallway of an apartment building, or garage?" (level 2) 3) "During the past 4 weeks, have you been to places in your immediate neighborhood, 
but beyond your own property or apartment building?" (level 3) 4) "During the past 4 weeks, have you been to places outside your immediate neighborhood but within your town?" (level 4) and 5) "During the past 4 weeks, have you been to places outside your immediate town?" (level 5) For each LS level, participants were asked how often they traveled to the particular area (<once a week, 1-3 times each week, 4-6 times each week, daily) and whether they needed assistance from another person or from an assistive device ("yes" or "no"). LSA was scored by assigning a value to each of the five levels and then adding the scores of each level. The level scores were obtained by multiplying the level number (1-5) by a value for independence $(2=$ "no assistance," 1.5 = "use of equipment only," 1 = "use of another person and/or equipment") further multiplied by a value for the frequency of movement $(1=$ once a week, $2=$ 1-3 times each week, $3=4-6$ times each week, and $4=$ daily) The LSA scores ranges from 0 ("totally bed-bound") to 120 ("traveled out of town every day without assistance").

Data on ADL were collected by interviewing the participants. IADL was assessed using a subscale of the Tokyo Metropolitan Institute of Gerontology index of competence, which contains five questions concerning "Instrumental self-maintenance" (shopping for daily living, preparing meals, paying bills, managing bank deposits and savings, and utilizing public transportation $)^{30)}$. The response to each item is "yes" (able to do) or "no" (unable). The total score is the number of items answered with a "yes." Thus, a higher score indicates a higher functional capacity.

Data were analyzed using SPSS software (Version 10.4; SPSS Inc., Chicago, IL).

The subjects were divided into two age groups: 75-79-year-olds and 80-84-year-olds. We used a $\chi^{2}$ test to compare certifications of need for long-term care, presence of disease, IADL, and LSA, and non-paired t-tests to compare other variables.

We classified pulmonary functional impairments into four categories based on ventilatory characteristics. Obstructive ventilatory impairment (OVI) was defined as $\%$ FEV $1.0<70 \%$, restrictive ventilatory impairment (RVI) as $\% \mathrm{VC}<80 \%$, combined ventilatory impairment (CVI) as $\%$ FEV $1.0<70 \%$ and $\% \mathrm{VC}<80 \%$, and normal ventilatory capacity (NVC) as $\% \mathrm{FEV} 1.0 \geq 70 \%$ and $\% \mathrm{VC} \geq 80 \%$. We compared the characteristics, the physical function, and mobility between the ventilatory function categories by one-way analysis of variance (ANOVA). When ANOVA indicated a significant effect, we used the Bonferroni post hoc test.

A p-value of $<0.05$ was considered to indicate statistical significance.

\section{RESULTS}

Table 1 presents the subject characteristics of the study participants. The height, body weight and grip strength of the subjects were similar to the national average ${ }^{31)}$. Accordingly, there was no regional deviation from the

Table 1. Characteristics of study subjects

\begin{tabular}{|c|c|c|}
\hline \multirow{2}{*}{$\begin{array}{l}\text { Age (years) } \\
\text { Number }\end{array}$} & $75-79$ & $80-84$ \\
\hline & 661 & 361 \\
\hline Height $(\mathrm{cm})$ & $148.5 \pm 5.4$ & $146.9 \pm 5.6$ \\
\hline Body weight (kg) & $50.3 \pm 7.7$ & $48.9 \pm 7.9$ \\
\hline BMI $\left(\mathrm{kg} / \mathrm{m}^{2}\right)$ & $22.8 \pm 3.5$ & $22.7 \pm 4.6$ \\
\hline SBP (mmHg) & $138.9 \pm 18.9$ & $139.0 \pm 19.6$ \\
\hline DBP (mmHg) & $76.8 \pm 10.3$ & $75.1 \pm 10.6$ \\
\hline Pulse (beats/min) & $77.6 \pm 10.8$ & $78.7 \pm 10.9$ \\
\hline Certification of care need & $51(7 \%)$ & $73(20 \%)^{* *}$ \\
\hline \multicolumn{3}{|l|}{ Contraction of disease } \\
\hline High blood pressure & $350(53 \%)$ & $206(57 \%)$ \\
\hline Hyperlipemia & $259(39 \%)$ & $134(37 \%)$ \\
\hline Anemia & $12(2 \%)$ & $13(4 \%)$ \\
\hline Apoplexy & $26(4 \%)$ & $25(7 \%)$ \\
\hline Diabetes & $58(9 \%)$ & $29(8 \%)$ \\
\hline Heart disease & $88(13 \%)$ & $60(17 \%)$ \\
\hline Osteoarthritis of the knee & $136(21 \%)$ & $92(26 \%)$ \\
\hline Osteoporosis & $187(28 \%)$ & $132(37 \%)^{* *}$ \\
\hline
\end{tabular}


Table 2. Physical function and mobility of study subjects

\begin{tabular}{lcc}
\hline Age (years) & $75-79$ & $80-84$ \\
\hline Number & 661 & 361 \\
Instrumental activity of daily living & $4.7 \pm 0.6$ & $4.5 \pm 0.9^{* *}$ \\
Life Space Assesment & $91.8 \pm 15.4$ & $85.2 \pm 18.4^{* *}$ \\
Grip strength(kg) & $19.0 \pm 4.0$ & $17.3 \pm 4.2^{* *}$ \\
Knee joint extension strength (newton•meter/kg) & $1.2 \pm 0.3$ & $1.1 \pm 0.3^{* *}$ \\
Comfortable gait velocity (meter/second) & $1.3 \pm 0.2$ & $1.1 \pm 0.3^{* *}$ \\
Maximal gait velocity (meter/second) & $1.7 \pm 0.3$ & $1.4 \pm 0.3^{* *}$ \\
Timed up-and-go (second) & $9.5 \pm 2.6$ & $11.3 \pm 4.0^{* *}$ \\
Maximal Timed up and go (second) & $6.9 \pm 1.6$ & $8.1 \pm 2.0^{* *}$ \\
One leg standing time with eyes open (second) & $29.6 \pm 22.0$ & $19.7 \pm 19.6^{* *}$ \\
\hline & & mean \pm standard deviation \\
& & $* *: \mathrm{p}<0.01$
\end{tabular}

Table 3. Pulmonary function of study subjects

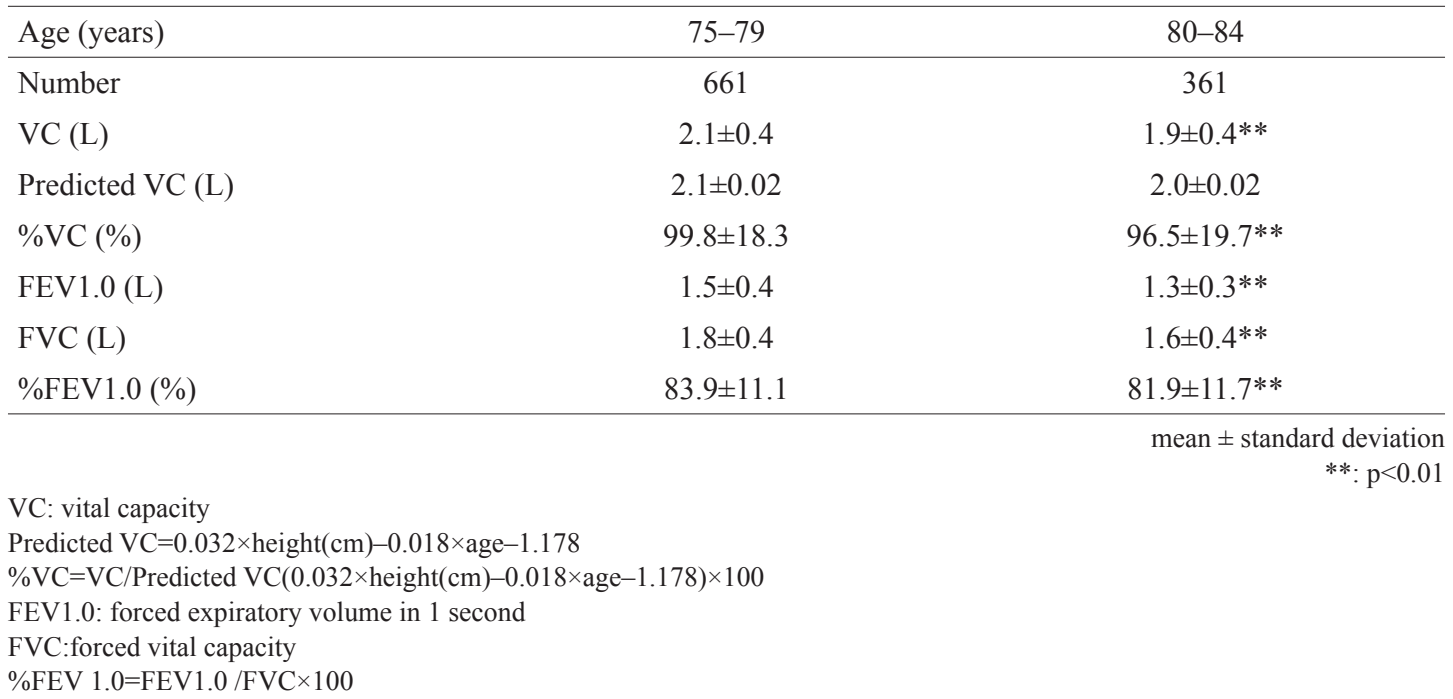

national average. The frequencies of certification of care need and osteoporosis were significantly higher in the group aged 80-84 years than the group aged 75-79 years $(p<0.01)$. Table 2 presents the results of physical functions and mobility tests and Table 3 shows the pulmonary function results. For all the measured variables in these tables, the group aged 80-84 years showed significantly inferior results compared to the group aged 75-79 years $(\mathrm{p}<0.01)$.

Table 4 lists the participants' physiological characteristics and the results of mobility assessments determined according to ventilatory function categories. Ventilatory function did not significantly affect the subject' physiological characteristics or mobility. Table 5 presents the results of the physical function tests as per ventilatory function category. Ventilatory function had statistically significant effects on the physical function as evidenced by one-way ANOVA. From the results of post hoc tests, the ventilatory disorder categories of RVI and CVI were found to be significantly associated with worse outcomes than the NVC and OVI disorder categories for many of the physical results.

\section{DISCUSSION}

Medical examinations of the elderly individuals generally serve the purpose of a screening examination for geriatric syndrome involving physical function, mobility, cognitive ability, and nutritional status. It has been hypothesized that the clinical deterioration of physical function and mobility are associated with pulmonary functional disorders. However, very few measurement variables for elucidating the functional integrity of the cardiac and pulmonary systems are known. In recent years, 
Table 4. Influence of ventilatory function on mobility

\begin{tabular}{lcccc}
\hline ventilatory functions & $\begin{array}{c}\text { Normal Ventilatory } \\
\text { Capacity }\end{array}$ & $\begin{array}{c}\text { Obstructive Ventilatory } \\
\text { Impairment }\end{array}$ & $\begin{array}{c}\text { Restructive Ventilatory } \\
\text { Impairment }\end{array}$ & $\begin{array}{c}\text { Combined Ventilatory } \\
\text { Impairment }\end{array}$ \\
\hline Number & 791 & 73 & 136 & 22 \\
Age & $78.3 \pm 2.6$ & $78.7 \pm 2.7$ & $78.9 \pm 2.8$ & $78.7 \pm 2.7$ \\
Height (cm) & $148.2 \pm 5.4$ & $148.7 \pm 5.8$ & $146.5 \pm 5.6$ & $145.6 \pm 4.7$ \\
Body weight $(\mathrm{kg})$ & $50.1 \pm 7.5$ & $49.2 \pm 7.5$ & $48.7 \pm 8.5$ & $45.6 \pm 9.3$ \\
BMI $\left(\mathrm{kg} / \mathrm{m}^{2}\right)$ & $22.6 \pm 4.7$ & $22.4 \pm 5.2$ & $22.1 \pm 4.7$ & $21.7 \pm 5.6$ \\
SBP $(\mathrm{mmHg})$ & $139.4 \pm 18.8$ & $137.8 \pm 20.3$ & $137.9 \pm 20.2$ & $134.4 \pm 21.5$ \\
DBP (mmHg) & $76.6 \pm 10.2$ & $75.9 \pm 10.7$ & $74.6 \pm 10.9$ & $72.1 \pm 12.6$ \\
Pulse (beats/min) & $78.3 \pm 10.9$ & $77.9 \pm 9.9$ & $75.7 \pm 10.5$ & $78.8 \pm 11.1$ \\
Instrumental activity of daily living & $4.6 \pm 0.8$ & $4.6 \pm 0.7$ & $4.5 \pm 0.9$ & $4.5 \pm 0.6$ \\
Life Space Assesment & $89.9 \pm 16.8$ & $92.2 \pm 13.4$ & $86.2 \pm 17.7$ & $84.8 \pm 18.6$ \\
Obstructive Ventilatory Impairment: \%FEV $1.0<70 \%$ & & & mean \pm standard deviation \\
Restructive Ventilatory Impairment: \%VC $<80 \%$ & & & \\
Combined Ventilatory Impairment: \%FEV $1.0<70 \%$ and \%VC<80\% & & &
\end{tabular}

Table 5. Influence of ventilatory functions on physical function

\begin{tabular}{|c|c|c|c|c|c|}
\hline Ventilatory function & $\begin{array}{l}\text { Normal } \\
\text { Ventilatory } \\
\text { Capacity }\end{array}$ & $\begin{array}{l}\text { Obstructive } \\
\text { Ventilatory } \\
\text { Impairment }\end{array}$ & $\begin{array}{l}\text { Restructive } \\
\text { Ventilatory } \\
\text { Impairment }\end{array}$ & $\begin{array}{l}\text { Combined } \\
\text { Ventilatory } \\
\text { Impairment }\end{array}$ & $\begin{array}{c}\text { Bonferroni } \\
\text { post hoc test }\end{array}$ \\
\hline Grip strength (kg) & $18.8 \pm 4.1$ & $18.6 \pm 3.7$ & $16.6 \pm 3.8$ & $16.4 \pm 4.8$ & $\begin{array}{l}\text { NVC vs RVI** } \\
\text { NVC vs CVI* } \\
\text { OVI vs RVI** }\end{array}$ \\
\hline Knee joint extension strength (newton $\bullet$ meter $/ \mathrm{kg}$ ) & $1.2 \pm 0.3$ & $1.1 \pm 0.3$ & $1.0 \pm 0.3$ & $1.0 \pm 0.4$ & NVC vs RVI** \\
\hline Comfortable gait velocity (meter/second) & $1.3 \pm 0.2$ & $1.3 \pm 0.2$ & $1.1 \pm 0.2$ & $1.0 \pm 0.2$ & $\begin{array}{l}\text { NVC vs RVI** } \\
\text { NVC vs CVI** } \\
\text { OVI vs RVI** } \\
\text { OVI vs CVI** }\end{array}$ \\
\hline Maximal gait velocity (meter/second) & $1.6 \pm 0.3$ & $1.6 \pm 0.3$ & $1.4 \pm 0.3$ & $1.4 \pm 0.4$ & $\begin{array}{l}\text { NVC vs RVI** } \\
\text { NVC vs CVI* } \\
\text { OVI vs RVI** } \\
\text { OVI vs CVI** }\end{array}$ \\
\hline Timed up-and-go (second) & $9.9 \pm 3.1$ & $9.9 \pm 2.6$ & $11.2 \pm 4.1$ & $12.1 \pm 4.8$ & $\begin{array}{l}\text { NVC vs RVI** } \\
\text { NVC vs CVI** } \\
\text { OVI vs RVI** } \\
\text { OVI vs CVI* }\end{array}$ \\
\hline Maximal Timed up-and-go (second) & $7.2 \pm 1.8$ & $7.1 \pm 1.4$ & $8.0 \pm 1.8$ & $8.5 \pm 3.0$ & $\begin{array}{l}\text { NVC vs RVI** } \\
\text { NVC vs CVI** } \\
\text { OVI vs RVI** } \\
\text { OVI vs CVI** }\end{array}$ \\
\hline One leg standing time with eyes open (second) & $26.8 \pm 21.7$ & $28.8 \pm 23.2$ & $21.3 \pm 19.8$ & $21.2 \pm 23.9$ & NVC vs RVI* \\
\hline
\end{tabular}

Obstructive Ventilatory Impairment: \%FEV 1.0 $\leq 70 \%$ mean \pm standard deviation

Restructive Ventilatory Impairment: $\% \mathrm{VC} \leq 80 \%$

Combined Ventilatory Impairment: $\% \mathrm{FEV} 1.0 \leq 70 \%$ and $\% \mathrm{VC} \leq 80 \%$ 
it has been reported that chronic obstructive pulmonary disease, which requires treatment by spirometry, occurs at a considerably high frequency in middle and old-aged residents of Japan ${ }^{32)}$. Consequently, the use of spirometry for the elderly population has been promoted; however, the actual optimal state of pulmonary function in the elderly and relationships between pulmonary function and physical function and mobility remain unclear.

Many studies have reported that pulmonary function declines with increasing age, and the rate of decline is accelerated among those of advanced aged ${ }^{23)}$. However, Pfitzenmeyer et al. found that individuals in the advanced age population who demonstrated good pulmonary function were stronger and generally survived for a longer time ${ }^{24)}$. Our results, like many other studies, indicate that advanced age as well as diminished physical function and mobility are associated with inferior (declining) pulmonary function.

Pulmonary function is related to exercise tolerance ${ }^{33)}$ and nutritional status ${ }^{34,35)}$. However, we do not agree with the opinion that a relationship exists between pulmonary function and mobility ${ }^{36,37)}$. Our results did not demonstrate a clear relationship between pulmonary function and mobility. According to Kazuhide et al., even if pulmonary function deteriorates in the elderly, it does not have an immediate influence on mobility ${ }^{38}$. Further, Carlos et al. reported that pulmonary function could predict the possibility of future health problems and possibly death ${ }^{39)}$. A restrictive ventilatory disorder is dependent on thoracic flexibility that is associated with ventilatory and respiratory muscular strength, both of which are susceptible to aging; it is believed that this influences mobility at some point in the future. The results of our study suggest that diminished pulmonary function is related to the physical function that support mobility. As for clinical implications, our results offer significant value for promoting preventive care. However, the group afflicted with OVI was not different from the group with NVC. For this reason, we believe that $65 \%$ of those with mild disease severity have RVI ${ }^{40}$.

An age-stratified study model must be used to clarify whether diminished pulmonary function influences mobility. In addition, males should also be included because the rates of decline of pulmonary function and physical function show sex differences. We can also prevent the decline of pulmonary function by certain specific interventions; however, we must clarify whether these measures would improve or maintain mobility. In this way, we may be able to contribute to a reduction in medical costs and improvements in the quality of life of the elderly.

\section{ACKNOWLEDGMENTS}

We thank the staff who helped conduct the study and also the women who extended their cooperation to our group. Special thanks to Dr Kim, Dr Hirano, Dr Yoshida and Dr Saito, who gave their generous support. I also thank my family who gave me the time to undertake this study.

\section{REFERENCES}

1) Ministry of Public Management, Home Affairs: Posts and
Telecommunications Statistics Bureau homepage: http://www.stat.go.jp/ data/jinsui/index.htm. (Accessed Nov. 1, 2010).

2) Suzuki T: Comprehensive mass health examination system for the community elderly - A new strategy for increase of physical fitness and for prevention of long-term care status. The Journal of Japan Academy of Health Sciences, 2004, 3: 133-138.

3) Kim HS, Tanaka K: The assessment of functional age using "Activities of Daily Living" performance tests. A study of Korean women. Journal of the American Psychoanalytic Association, 1995, 3: 39-53.

4) Nagasaki $H$, Itoh $H$, Furuna $T$, et al.: The structure underlying physical performance measures for older adults in the community. Aging Clinical and Experimental Research, 1995, 7: 451-458.

5) Kinugasa T, Nagasaki H, Furuna T, et al.: Physical performance measurement for characterizing high function older persons. Journal of Aging and Physical Activity, 1996, 4: 338-348.

6) Furuna $T$, Nagasaki H, Nishizawa $S$, et al.: Longitudinal change in the physical performance of older adults in the community. Journal of the Japanese Physical Therapy Association , 1998, 1: 1-5.

7) Daubney ME, Culham EG: Lower extremity muscle force and balance performance in adults aged 65 years and older. Phys Ther, 1999, 79: 11771185.

8) Suzuki T, Yoshida H, Kim H, et al.: Walking speed as a good indicator for maintenance of I-ADL among the rural community elderly in Japan. Geriatric Gerontology International, 2003, 3: 6-14.

9) Yoshida H, Suzuki T, Kim H, et al.: Effects of osteoporotic fractures on quality of life-related variables in the community elderly in Japan; an 8-year follow-up study in TMIG-LISA. Geriatric Gerontology International, 2003, 3: $50-54$.

10) Janssens JP, Pache JC, Nicod LP, et al.: Physiological changes in respiratory function associated with aging. Eur Respir J, 1999, 13: 197-205.

11) Meyer KC: Aging. Proceedings of the American Thoracic Society, 2009, 2 : 433-439.

12) Nishizawa T: The change of the lungs function. Circular Breathing, 2002, 50: 665-668.

13) Klock RA: Influence of aging on the lung. New York: Van Nostrand Reinhold, 1977, pp432-444.

14) Chan ED, Welsh CH: Geriatric respiratory medicine. Chest, 1998, 114: 1704-1733.

15) Turner JM, Mead J, Wohl ME: Elasticity of human lungs in relation to age. J Appl Physiol, 1968, 25: 664-671.

16) Crapo RO, Morris AH, Clayton PD, et al.: Lung volumes in healthy nonsmoking adults. Bulletin of European Physiopathology and Respiration, 1982, 18: 419-425.

17) Knudson RJ: Aging of the respiratory system. Current Pulmonology, 1989, 10: $1-24$.

18) Anthonisen NR, Danson J, Robertson PC, et al.: Airway closure as a function of age. Respir Physiol, 1970, 8: 58-65.

19) Chen HI, Kuo CS: Relationship between respiratory muscle function and age, sex, and other factors. J Appl Physiol, 1989, 66: 943-948.

20) Enright PL, Knormal RA, Manolio TA, et al.: Respiratory muscle strength in the elderly: correlates and reference values. Am J Respir Crit Care Med, 1994, 149: 430-438.

21) Suzuki M, Teramoto N: An aging change of the maximum expiratory muscular strength and the maximum inspiratory muscular strength. Japanese Journal of Thoracic Diseases, 1997, 35: 1305-1311.

22) Burrows B, Cline MG, Kundson MJ, et al.: A descriptive analysis of the growth and decline of the FVC and FEV1.0. Chest, 1983, 83: 717-724.

23) Camili AE, Burrows B, Kundson MJ, et al.: Longitudinal changes in forced expiratory volume in 1 second in adult: methodological considerations and findings in healthy nonsmokers. Am Rev Respir Dis, 1986, 133: 974-980.

24) Pfitzenmeyer P, Laurent B, Philippe D, et al.: Lung function in advanced age: Study of ambulatory subjects aged over 75 years. Gerontology, 1993, 39: $267-275$.

25) Senzyu H: The chest rehabilitation of the pulmonary emphysema. Kyoto: Kinboudou, 1998, pp131-141.

26) The Japanese Respiratory Society: The Pulmonary Function Test Guidelines, Tokyo: Medical View 2004.

27) Podsiadlo D, Richardson S: The Timed "Up \& Go": a test of basic functional mobility for frail elderly persons. J Am Geriatr Soc, 1991, 39: $142-148$.

28) Baker PS, Bodner EV, Allman RM: Measuring life-space mobility in community-dwelling older adults. J Am Geriatr Soc, 2003, 51: 1610-1614.

29) Abe T, Hashidate H, Shimada $H$, et al.: The association of activity assessed by Life-Space Assessment with physical function and instrumental activities of daily living in elderly people. Rigakuryoho Kagaku, 2009, 24: 721-726.

30) Koyano W, Shibata H, Nakazato K, et al.: Measurement of competence: 
reliability and validity of the TMIG Index of Competence. Archives of Gerontology and Geriatrics 1991, 13: 103-116.

31) Ministry of Education, Culture, Sports, Science and Technology: Physical functions investigation in 2008: http://www.mext.go.jp/b_menu/toukei/001/ index22.htm (Accessed Dec. 10, 2010).

32) Fukuchi $Y$, Nishimura M, Ichinose $M$, et al.: COPD in Japan: Nippon COPD Epidemiology study. Respirology, 2004, 9: 458-465.

33) Senzyu Y, Ouike T, Kurita K, et al.: About breathing muscular strength and the lungs function of the CPOD patient, relevance with the exercise tolerance. Nagasaki University Medical Department Bulletin, 2002, 15: 9-14 (in Japanese).

34) Tashiro T, Urata H, Senzyu H, et al: Breathing muscular strength and the lower limbs muscular strength of the COPD patient, a study about the nourishment state. Nagasaki University Medical Department Bulletin, 2002, 15: 1-8 (in Japanese).

35) Morimoto M, Takai K: The relationship between functional impairments and activities of patients with chronic obstructive pulmonary disease. Journal of the Japanese Academy of Nursing Science, 2004, 24: 13-20 (in Japanese).
36) Prigatano P, Wright E, Levin D, et al.: Quality of life and its predictors in patients with mild hypoxemia and Chronic Obstructive Pulmonary Disease. Archives of Internal Medicine, 1984, 144: 1613-1619.

37) Jones P, Baveystock C, Littlejohns P: Relationships between general health measured with the sickness impact profile and respiratory symptoms, physiological measures, and mood in patients with chronic airflow limitation. American Review of Respiratory Disease, 1989, 140: 1538-1543.

38) Tomita K, Okazaki D, Akai Y, et al.: Actual conditions survey of respiratory muscle weakness in community dwelling elderly people - A preliminary cross-sectional study in Gunma mountain area. Physiotherapy Gunma, 2008, 19: 13-19 (in Japanese).

39) Carlos A, Evelyne A, Peter H, et al.: Peak Expiratory Flow as a Predictor of Subsequent Disability and Death in Community-Living Older Persons. J Am Geriatr Soc, 2008, 56: 1014-1020.

40) Pauwels R, Buist A, Ma P, et al.: Global strategy for the diagnosis, management, and prevention of chronic obstructive pulmonary disease: National Heart, Lung, and Blood Institute and World Health Organization Global Initiative for Chronic Obstructive Lung Disease (GOLD): executive summary. Respiratory Care, 2001, 46: 798-825. 